\title{
Construcción sociocultural de San Salvador de Jujuy, frontera simbólica de Argentina con Bolivia
}

\section{Sociocultural construction of San Salvador de Jujuy, the symbolic border between Argentina and Bolivia}

Melina Gaona*a (i) (http://orcid.org/0000-0002-2960-5957)
Recibido el 13 de mayo de 2016 Aceptado el 15 de diciembre de 2016.

*Autor para correspondencia: Melina Gaona, correo electrónico: melina.d.gaona@gmail.com

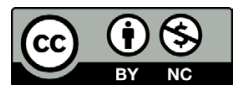

Todos los contenidos de Estudios Fronterizos se publican bajo la licencia Creative Commons Atribución no comercial 2.5 México, y pueden ser usados gratuitamente para fines no comerciales, dando el crédito a los autores y a la revista Estudios Fronterizos.
${ }^{a}$ Centro de Estudios de Historia, Cultura y Memoria, Universidad Nacional de Quilmes, Argentina, correo electrónico: melina.d.gaona@gmail.com

\section{Resumen}

Se analiza la ciudad de San Salvador de Jujuy como espacio fronterizo y espacio de ciudad. Mediante la sistematización de estudios locales se busca considerar los elementos históricos, políticos, socioeconómicos, migratorios y simbólicos que crean la experiencia urbana de frontera. Este aporte se acota a reconstruir a la ciudad como una red de sentidos. Se profundiza en los flujos migratorios, la situación política reciente, la impresión en la urbanidad de las desigualdades económicas y, la relevancia de lo mediático y lo ritual en la configuración de los sentidos de ciudad dominantes; se consignan los factores que territorializan la diferencia y la desigualdad local y el proceso de periferización y pauperización del suelo. Por otro lado, se determinan los conflictos políticos recientes que inciden en la desarticulación regional y las disputas simbólicas que tensionan la pertenencia nacional frente a la alta incidencia andina.

Palabras clave: espacios de frontera, espacios de ciudad, sentidos de ciudad.

\section{Abstract}

The city of San Salvador de Jujuy is analyzed both as a border space and as a city space. Through the systematization of local studies, the aim is to consider the historical, political, socioeconomic, migratory and symbolic elements that create the urban border experience. This contribution focuses on reconstructing the city as a network of senses. It deepens our understanding of migratory flows, the recent political situation, the impact of economic inequality on urbanisms, and the relevance of media and ritual acts in the configuration of dominant senses in cities. In addition, the factors that demarcate the difference and local inequality and the process of peripheralization and impoverishment of the soil are examined. Both the recent political conflicts that affect regional disarticulation and the symbolic disputes that cause tension in national belonging against a strong Andean influence are outlined.

Keywords: border spaces, city spaces, senses of a city.

CÓMO CITAR: Gaona, M. (2017). Construcción sociocultural de San Salvador de Jujuy, frontera simbólica de Argentina con Bolivia [Sociocultural construcion of San Salvador de Jujuy, the symbolic border between Argentina and Bolivia]. Estudios Fronterizos, 18(36), 54-77, doi:10.21670/ref.2017.36.a03 


\section{Introducción y construcción teórica para el análisis}

La intención de este artículo es construir analíticamente a la ciudad de San Salvador de Jujuy en sus dimensiones históricas y más contemporáneas para considerar los factores migratorios, socioeconómicos y políticos que inciden materialmente en la estructuración actual de la construcción simbólica de la ciudad capital de la provincia de Jujuy, límite con la frontera boliviana y chilena en Argentina. El hecho de ser el punto extremo norte de la nación Argentina, y con una composición poblacional con alta incidencia étnica andina y de migrantes bolivianos, la ubica en una constante tensión cultural en la demanda por pertenencia nacional.

El desarrollo de este artículo se da en el marco de una investigación que analiza las derivas político-culturales en la construcción de un espacio de ciudad específico, como es San Salvador de Jujuy. Puntualmente, dividimos este artículo en los siguientes ejes: a) introducción, donde se desarrollan los conceptos clave sobre los cuales asentamos la investigación; $b$ ) la configuración de un espacio de frontera y de periferia en la nación, b1) la conformación poblacional a partir de los procesos migratorios, b2) los factores sociopolíticos de las últimas décadas y su condicionamiento sobre los ciudadanos; $c$ ) la construcción social de la ciudad, $c 1$ ) la configuración del hábitat urbano, $c 2$ ) el desarrollo de la expansión popular en Alto Comedero, como proceso de periferización de la ciudad; y $d$ ) los sentidos de ciudad dominantes, $d 1$ ) los discursos sobre la ciudad en el espacio mediático; $d 2$ ) las articulaciones identitarias hegemónicas sobre todo a partir de los discursos "ahistorizantes" y los rituales de tradicionalización, y por último, se presenta la sistematización de conceptos y conclusiones.

Más allá de las características específicas que hacen a la particularidad del caso elegido, en la ciudad de San Salvador de Jujuy se exhiben procesos similares a los que acontecen en distintas latitudes a nivel nacional y latinoamericano en lo que respecta a fronteras socioculturales, periferización y expansión urbana no planificada estatalmente; la gubernamentalidad ${ }^{1}$ y los conflictos sociales.

Asumimos como punto de partida que pensar una ciudad es pensar sus redes históricas, las materialidades sobre las que se va cimentando, los trazos mediante los cuales se narran tanto sus pasados como sus presentes, las voces, las visibilidades, las identidades, los discursos mediáticos, sus festividades, etcétera.

Así, se retoma a San Salvador de Jujuy como "espacio social" en el sentido que le da Massey (2005): constituido a partir de las interrelaciones, posibilitador de la multiplicidad y la pluralidad en coexistencia; en permanente construcción, por ende, nunca cerrado y eminentemente político.

De esta concepción del espacio social desprendemos otras tres definiciones que sirven a la interpretación del territorio urbano como ámbito de desenvolvimiento de las disputas, materializaciones y subjetivaciones planteadas: el espacio fronterizo, los espacios de ciudad y, los sentidos de ciudad. Cada uno de estos conceptos es confluyente y funcionan como puntos de partida teóricos para entender a la ciudad.

Incorporamos el concepto de espacio fronterizo desde una tradición teórica que considera a la frontera, la nación y el Estado desde perspectivas que no se detienen

\footnotetext{
${ }^{1}$ Cabe la definición del concepto de Foucault (2006) como: las instituciones, procedimientos y tácticas que permiten un ejercicio específico de poder sobre la población; la tendencia hacia la preeminencia de este poder por sobre otros, mediante la fórmula llamada "gobierno"; y el proceso mismo de "gubernamentalización" del Estado.
} 
sobre la constitución jurídica del límite, sino que se abocan sobre todo a los efectos y las subjetivaciones de las operaciones históricas de nacionalidad. Es así que el espacio de frontera se presenta como la elaboración cultural y simbólica de dicha fronterización (Benedetti, 2014). Para ello es necesario atender al carácter contingente, sujeto al tiempo y a la acción humana de las fronteras (Grimson, 2000).

Por otro lado, al someter al análisis a un territorio urbano utilizamos una definición productiva a dichos fines como es la de los "espacios de ciudad" y, subsumida en ella, la de los "sentidos de ciudad". La producción del espacio de ciudad no se da de manera lineal, ni de una vez para siempre; sino que la ciudad se entreteje en una constante disputa condicionada por las relaciones de poder, de producción y de consumo, y de visibilización de los actores, atravesados por los sentidos atribuidos a cada lugar. Como espacio de ciudad responde a dinámicas internas en las que se expresan distintas instancias de relaciones de poder, traducidas en lugares, y se constituye en diálogo con elementos de figuración acerca del afuera, como parte del mapa que ubica imaginariamente a la ciudad con un horizonte de expectativas, valores y deseos respecto de la relación con tal exterior constitutivo.

A su vez, los sentidos de ciudad son "social e históricamente construidos" (García, 2010a, p. 18) de manera simultánea en varias escalas, y están vinculados con un conjunto de relaciones de poder específicas. Estos sentidos se configuran a partir de la experiencia más cotidiana de proximidad, como a partir de sentidos más arraigados en la memoria colectiva y los imaginarios sociales que circulan y se sostienen sobre todo a través de mediatización de los discursos (Burgos y García, 2008), las representaciones cartográficas (García, 2003) y los rituales (Gaona, 2015). ${ }^{2}$

Existe al interior de cada ciudad una disputa entre los sentidos hegemónicos acerca de lo que representa y de los actores en ella, intentando homogeneizarla y unificarla, y existen de igual manera, una serie de heterogeneidades que la hacen una y varias ciudades a la vez. La diversidad de actores, de experiencias de ciudad, de tránsitos, accesos y condiciones de habitabilidad la hacen particular para cada uno (García, 2010a).

Las distintas modalidades de construcción de sentidos de ciudad que se presentan tienen que ver con la intención de narrar la ciudad y los procesos hegemónicos que en ella ocurren como una red, una "red de simultaneidades históricas" a fin de desplegarla como discurso temporalmente sucesivo (Bolle, 2008, p. 30). Toda esta serie de materiales nos permiten esbozar una cartografía sociocultural local.

Estos planteos teóricos hacen parte de la antesala cognitiva para un análisis de la urbanidad desde una perspectiva que pretende tener presente la coyuntura. ${ }^{3}$ Para ello debemos atender a la materialidad de las condiciones, la sobredeterminación histórica específica y la provisoriedad de las relaciones de fuerzas, lo que promete adentrarnos analíticamente en las negociaciones y rearticulaciones permanentes entre los poderes (Grimson, 2009). La definición y localización de la coyuntura por teorizar requiere ocuparnos de rastrear el modo en el que se anudan las imágenes que van construyendo sentidos contextuales del territorio.

${ }^{2}$ Las referencias bibliográficas señaladas en este párrafo corresponden específicamente a estudios realizados en San Salvador de Jujuy y hacen al mapa de interpretación de los procesos hegemónicos de constitución de la ciudad.

${ }^{3}$ Cuando en este abordaje se habla de coyuntura, se lo hace sobre todo en el sentido en el que lo dan Hall (2010b) y Grossberg (2006), y que retoman distintos autores desde los estudios culturales latinoamericanos. 
$\mathrm{Al}$ analizar una urbanidad como la jujeña debemos entonces pensar cada imagen local como una escena en espiral, que en este caso se mueve a través de lo global, Latinoamérica y la región andina; la nación Argentina, el noroeste y la frontera; la provincia y la región de valles; entre las que además circulan una acumulación histórica frente a cada una. No obstante, imaginar la ciudad como un espacio local, en un contexto de cruces tan particulares como el jujeño, requiere asumir la agencia de lo local por sobre los rumbos de lo global, lo nacional o inclusive lo regional (Massey, 2005). Con esto nos referimos a las dificultades comunes para observar coyunturas específicas en los contextos de análisis, cuando los terrenos de lo analizado no son de las proximidades de lo más habitualmente visto en el ámbito académico, político o mediático. Una buena parte de los estudios sobre ciudades refieren a contextos en los que se tienen más presentes nociones como metrópolis, ${ }^{4}$ megaciudades (Bolle, 2008), megalópolis (Freitag, 2012), o el rol de las ciudades periféricas en función de las ciudades globales (Sassen, 1999). Son comunes las alusiones a caracteres latinoamericanos, argentinos, del noroeste argentino, como si fuera posible amalgamar en una metalepsis toda una serie de procesos históricos diferenciados y marcos culturales particulares. Más allá de esto, ha existido una tradición que considera los factores fundacionales de las urbanidades latinoamericanas en torno de la colonia y la configuración de los Estados-Nación (Martínez, 1997; Rama, 1998; Romero, 2010). Todas estas advertencias son tenidas en cuenta a la hora de construir una problematización que considere a San Salvador de Jujuy, una ciudad mediana, capital de una provincia de frontera (Véase Figura 1).

Figura 1: Mapa Sudamérica

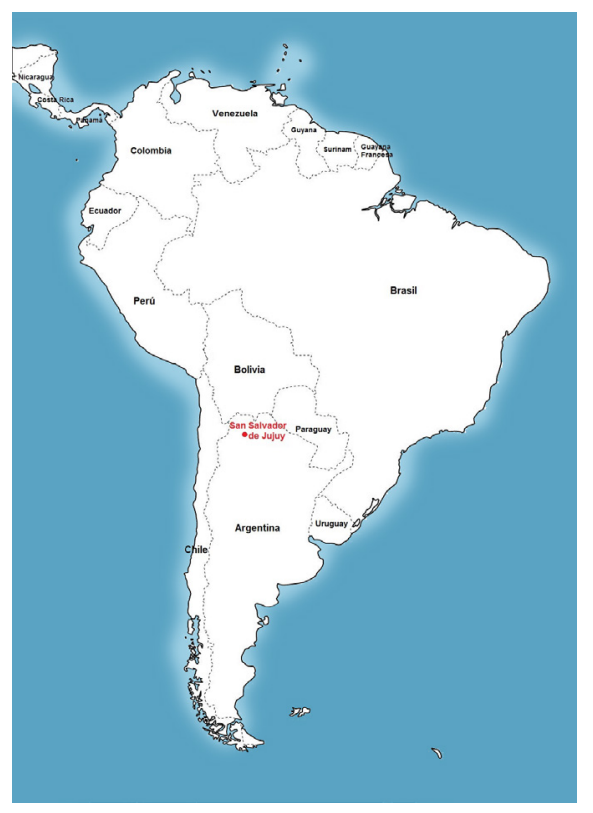

Fuente: Elaboración propia.

${ }^{4}$ Concepto, por otra parte, que sostiene con gran vigencia los planteos de Simmel (2004) y Benjamin (2005). 
Para este artículo concretamos una sistematización de datos y resultados de otras investigaciones locales y de organismos nacionales e internacionales, en contraste con datos generados por nosotros mismos. Esta información fue recogida de manera que resulte productiva para el sostenimiento de la problematización inicial. Asimismo esta síntesis parcial del conocimiento producido acerca de la ciudad de San Salvador de Jujuy se concibe como un elemento más de los sentidos acerca de la ciudad. El objetivo fundamental al establecer un recorrido por la agenda académica respecto del tema es dejar sentada esta sistematización como base para líneas posibles de análisis a futuro.

\section{La configuración periférica de la frontera}

\section{Proceso migratorio y configuración poblacional}

A continuación podemos introducir una construcción analítica propiamente dicha de la ciudad de San Salvador de Jujuy. Primeramente, debemos ubicarla como la ciudad capital de una provincia (Jujuy), perteneciente al departamento Manuel Belgrano, y ubicada en la región noroeste de la Argentina sobre el valle surandino. ${ }^{5}$

El crecimiento más marcado de la ciudad de San Salvador de Jujuy se da sobre todo durante la primera mitad del siglo xx. Si el Gran Buenos Aires creció más de $200 \%$ durante ese periodo, San Salvador de Jujuy lo hizo en 579\% (García, 2010). Este marcado crecimiento no está vinculado con el fenómeno de las masas advenidas de ultramar, proceso migratorio al que habitualmente se alude a la hora de considerar los modos en los que "fue poblada" la nación argentina. Al contrario, el corte en la mayor escalada de inmigración europea (hasta la década de 1930) coincide con el momento de mayor expansión demográfica de la ciudad norteña, debido sobre todo a la inmigración boliviana (Caggiano, 2005; García, 2010), altamente involucrada con la producción zafrera y minera.

La inmigración boliviana entre fines del siglo xix y principios del xx se sostiene sobre todo debido a los trabajadores migrantes de las cosechas zafreras, destacándose en la provincia el asentamiento sobre la zona del Ramal (Jerez y Rabey, 2006). A esta actividad, que tenía las características del trabajo golondrina, se le sumaron a partir de la década de 1930 otras actividades agrícolas, sobre todo la de la producción de tabaco. Debido a que este tipo de producción se valía de la mano de obra (impaga) también de mujeres y niños, familias enteras terminaron estableciéndose definitivamente en la provincia (Sassone, 2009). Todo este periodo se extiende entre 1870 y fines de 1960. Esta tendencia hacia la concentración demográfica se da en un periodo posterior como marcado drenaje (1960-1985) desde la región andina y fronteriza, la Puna y la Quebrada, hacia las regiones bajas, más cercanas al corazón administrativo de la provincia (Stumpo, 1992). Ya para la década de los años noventa, la población oriunda del país limítrofe censada señalaba un marcado envejecimiento y feminización (Sala, 2012), que además se concentraba sobre todo en las regiones más densamente pobladas; y si bien

\footnotetext{
${ }^{5}$ En la provincia se reconocen cuatro grandes regiones: la Puna (Santa Catalina, Yavi, Rinconada, Cochinoca y Susques), la Quebrada (Humahuaca, Tumbaya y Tilcara), las Yungas y el Ramal (Valle Grande, Ledesma, San Pedro y Santa Bárbara), y los Valles (Manuel Belgrano —San Salvador de Jujuy, Reyes y Yala-, San Antonio, Palpalá y El Carmen).
} 
la inmigración boliviana ha tenido un marcado descenso, se ha sostenido constante hasta la actualidad. ${ }^{6}$

De la población actual de la capital provincial 3.28\% es procedente de Bolivia; mientras que el número para el conjunto de la provincia asciende a $4.1 \%$, lo que demuestra una tasa aún alta de migración limítrofe. Este número es más elevado que aquel que se encuentra en otras latitudes nacionales como pueden ser la provincia también limítrofe de Salta $(1.85 \%)$, la capital federal $(2.65 \%)^{7}$ o el conurbano bonaerense $(1.15 \%)$ (Instituto Nacional de Estadísticas y Censos [Indec], 2012).

Este proceso, sostenido a lo largo de casi un siglo, opera articulando las identificaciones locales, ciertas adscripciones, tensiones y rechazos internos frente a la demanda por pertenencia nacional (Caggiano, 2005).

De acuerdo con el censo 2010 (Indec, 2012), se congregan en la ciudad capital 265 249 habitantes, lo que supone casi $40 \%$ de la población provincial en una superficie que corresponde solo a 3\% del territorio provincial total. Esta primera muestra de la concentración poblacional en un sector urbano en la provincia se confirma al señalar que otro $37 \%$ de la población está reunido en solo tres ciudades (El Carmen, Ledesma y San Pedro). ${ }^{8}$ Si consideramos que San Salvador de Jujuy, Palpalá y El Carmen (con los pueblos de Perico y El Carmen), ciudades contiguas en el mapa provincial, reúnen a 2 de cada 3 habitantes de Jujuy podemos convalidar el argumento acerca de la aglomeración urbana en la que se concentra la población jujeña.

Este fenómeno acumulativo de la población genera una fuerte desarticulación entre los distintos sectores de la provincia, entre un drenaje histórico de las zonas altas (Karasik, 2005) y un marcado crecimiento urbano en las regiones productivas más dinámicas, —basadas sobre todo en la centralización de la administración pública-y en el sector privado, a partir del tabaco y la caña.

\section{Factores sociopolíticos recientes}

Hacia finales del siglo xx, a las asimetrías históricas generadas a partir de la postergación económica regional y un estancamiento en el crecimiento industrial local, se le agrega el cimbronazo económico, productivo y social que significó para el conjunto de la provincia la opción del gobierno nacional con la presidencia de Carlos Menem, por las medidas hacia la instalación de un modelo neoliberal y una ideología conservadora como rumbo de los destinos federales. El experimento de la desregulación del mercado, eliminación del proteccionismo, intervención del Estado en la presión tributaria y

${ }^{6}$ Para los censos de 2001 y 2010 sobre $4.86 \%$ y $4.42 \%$ de población migrante sobre el total de la población, respectivamente $4.56 \%$ y $4.11 \%$ correspondían a personas nacidas en Bolivia. Para un mayor contraste entre el carácter de los flujos de inmigración boliviana y chilena, podemos señalar que en ambos censos frente a casi $94 \%$ de bolivianos entre el total de los inmigrantes presentes en Jujuy, solo $1.8 \%$ de aquel total correspondía a inmigrantes chilenos (Indec, 2012).

${ }^{7}$ Mientras que los números de los migrantes en la franja de población en edad de trabajar en la ciudad de Buenos Aires ascienden a casi $90 \%$, la cantidad de habitantes mayores a 65 años solo corresponde a $3 \%$ sobre el total de bolivianos en la ciudad. En cambio, el número de personas migrantes bolivianas mayores a 65 años en la provincia de Jujuy llega a casi $30 \%$. Esto habla de la variación en los destinos de los flujos de migración boliviana en distintas décadas del siglo pasado.

${ }^{8}$ Por su parte, el departamento Palpalá, colindante con el departamento Manuel Belgrano, concentra a otro $7.81 \%$ de la población provincial (Dirección Provincial de Estadísticas y Censos [DiPEC], 2012). 
transferencia de la renta a los sectores económicos más altos, el desfinanciamiento de la seguridad social y el desguace de las empresas públicas con posterior venta a capitales privados coordinó todos los elementos para una metamorfosis social que devino en el incremento de los índices de desigualdad iniciados hacía décadas en la provincia, fomentando altísimos niveles de desempleo, exclusión y marginalidad (Lagos y Gutiérrez, 2009). Tal como afirman Lagos y Gutiérrez (2009), estas políticas afectaron de manera más pronunciada a las regiones periféricas del país, por no tener una inserción clara en el nuevo modelo.

Palpalá, ciudad colindante con San Salvador de Jujuy y cuna de la siderúrgica Altos Hornos Zapla, es un territorio paradigmático para considerar lo que supuso el traspaso de empresas públicas al sector empresarial privado, sobre todo en una provincia con bajos índices de empleo generado a partir de la industria (Jerez, 2015). La agudización de la falta de empleo a partir de la reducción de mano de obra debido a las privatizaciones provinciales a inicios de la década de los años noventa, como parte del proceso que transcurría como receta económica a nivel nacional, supuso un destino laboral incierto, desconcierto en los sectores de mano de obra no técnica, y un desbarajuste generalizado entre las familias de los empleados desocupados. Buena parte de la población involucrada en este sector de la producción se vio obligada a recurrir al cuentapropismo, los microemprendimientos y a la dependencia de planes sociales (Bergesio, Golovanevsky y Marcoleri, 2009b). Esto y procesos similares de supresión del empleo generaron una escalada conflictiva en los sectores urbanos de la provincia que se instalaron mediante luchas crónicas a lo largo de toda la década en forma de piquetes, marchas, huelgas, tomas y acampes.

A nivel nacional, las percepciones de inestabilidad y crisis económica se sintieron de forma más pronunciada después de mediados de la década de los años noventa, con un estallido generalizado ya durante el gobierno del presidente De la Rúa en diciembre de 2001. Sin embargo, en Jujuy ya a fines de la década de los ochenta y durante toda la siguiente década se sufrió una situación de "ingobernabilidad" (Lagos y Gutiérrez, 2009, p. 102), anticipándose diez años a la crisis nacional, a causa de la falta de poder de decisión por parte del gobierno provincial, la marcada disputa a partir de intereses patrimonialistas por parte de los gobernantes, la inacción frente al desempleo, y la crisis económica. Esto provocó que la provincia se ajustara políticamente al tránsito de ocho gobernadores a lo largo de la década, con una caída virulenta y conflictiva en el caso de cuatro de ellos ${ }^{9}$ (Lagos y Gutiérrez, 2006).

Así, el periodo identificado históricamente como de mayor declive económico y debacle de la institucionalidad política a nivel nacional —años 2001-2002- se experimentó a nivel local como línea de continuidad de un conflicto de muy larga data, que, en cambio, encontró a la provincia en una relativa estabilidad gubernamental, habiendo sostenido por primera vez en varios años, a un mismo gobernador en el poder —durante los tres años antecedentes-.

No obstante, la crisis económica se sostuvo ya como marca estructural de la experiencia local y la población bajo la línea de pobreza para ese año alcanzaba $68.1 \%$, de acuerdo con el Indec (Lagos y Gutiérrez, 2009). Entre 1980 y 2002, de las provincias

\footnotetext{
${ }_{9}^{9}$ Ricardo De Aparici renuncia (1987-1990); Eduardo Huáscar Alderete completa el mandato del anterior (1990-1991); Roberto Rubén Domínguez renuncia (1991-1993); José Carlos Ficoseco renuncia (19921994); Oscar Agustín Perassi completa el mandato de los dos anteriores (1994-1995); Guillermo Eugenio Snopek fallece (1995-1996); Carlos Alfonso Ferraro renuncia (1996-1998); Eduardo Alfredo Fellner completa el mandato, y es electo y reelecto (1998-2007) (Lagos y Gutiérrez, 2006).
} 
del Noroeste, las cuales muestran niveles más bajos de producción y empleo que el resto del país, Jujuy registró la tasa de actividad promedio y de empleo más bajas de la región (Martínez, Golovanevsky y Medina, 2010).

La situación local se desdobló en dos modos de experimentación de la ciudadanía política. Por un lado, como parte del giro conservador promulgado por las lógicas neoliberales, un gran sector de la población se volcó a una anomia despolitizada traducida en la mediatización de la política tradicional. ${ }^{10}$ Por otro lado, la emergencia del movimiento de desocupados y la fuerza que adquirieron parte de los sindicatos estatales $^{11}$ se tradujeron en una potente resistencia popular frente a gobiernos provinciales débiles, un marcado uso de la fuerza oficial para combatir la protesta y un clima generalizado a lo largo de toda la década de beligerancia social e inestabilidad gubernamental.

Se configura un mapa a grandes rasgos de la ciudadanía local con: un sector de la población que se desvincula de la acción participativa política, un sector tendiente al conflicto público en razón de demandas sobre todo de clase frente al Estado, y un gobierno caudillista que responde a los rumbos federales sin un fuerte peso de reconocimiento y legitimidad local.

Así también, como otro de los vectores de este mapa, y al presentarse en las últimas décadas un panorama desmovilizante por parte de los cuadros desde los partidos tradicionales, podemos considerar que la historia política de Jujuy reciente se ve plenamente guiada por la lucha de los movimientos sociales: sindicales, de organizaciones piqueteras, del movimiento indígena, del movimiento de Derechos Humanos, etcétera (Gaona y López, 2013; Karasik y Gómez, 2015; Kindgard, 2009; Rodríguez, 2002).

\section{La construcción social de la ciudad}

\section{De lo topográfico a los sentidos del habitar urbano}

Estas modificaciones en la convivencia urbana se tradujeron también en un agravamiento de las marcas de desigualdad territorial, a partir de la marcada expansión de asentamientos populares y las disputas por la cesión de terrenos y condiciones de hacinamiento en la zona sur de la ciudad. Por otra parte, se terminaron de consolidar en los sentidos de ciudad una marcada distancia entre lo que acontece entre los ríos

\footnotetext{
${ }^{10}$ Esto se vincula también con la modificación en los consumos a partir del acceso al servicio de televisión por cable privado con transmisión casi exclusivamente de contenidos producidos en la región de la capital nacional, y por otro lado, a la influencia y la marcada parcialidad en la producción mediática local influida por el uso discrecional de la pauta oficial a nivel local (García, Arrueta y Brunet, 2009).

${ }^{11}$ Kindgard (2009) reconoce que la tendencia alineada con el gobierno por aquellos años por parte de la Confederación General del Trabajo (CGT) generó la necesidad de la expresión de demanda y de lucha a partir de nuevos sindicatos disidentes: el Movimiento de Trabajadores Argentinos (MTA), la Corriente Clasista y Combativa (ccc) y la central obrera independiente Central de Trabajadores de la Argentina (CTA). En Jujuy, durante los años de mayor conflicto tiene una gran preponderancia el Frente de Gremios Estatales (FGE), el cual, entre otros gremios contaba con el Sindicato de Empleados y Obreros Municipales (SEOM), con el Perro Santillán como figura rutilante en las luchas de la década. Otra de las configuraciones claves de la época a nivel político es la Multisectorial, compuesta por sindicatos, organizaciones de estudiantes y colegios profesionales.
} 
Grande y Chico (o XibiXibi), y el resto de la ciudad (Véase Figura 2). Este encuadre fundacional urbano entre ambos ríos va a marcar históricamente los modos de experimentación de la ciudad, organizando en torno de este la mayor parte de las actividades políticas, administrativas, comerciales y turísticas ${ }^{12}$ de la ciudad (García, 2000).

Figura 2: Mapa de la ciudad de San Salvador de Jujuy

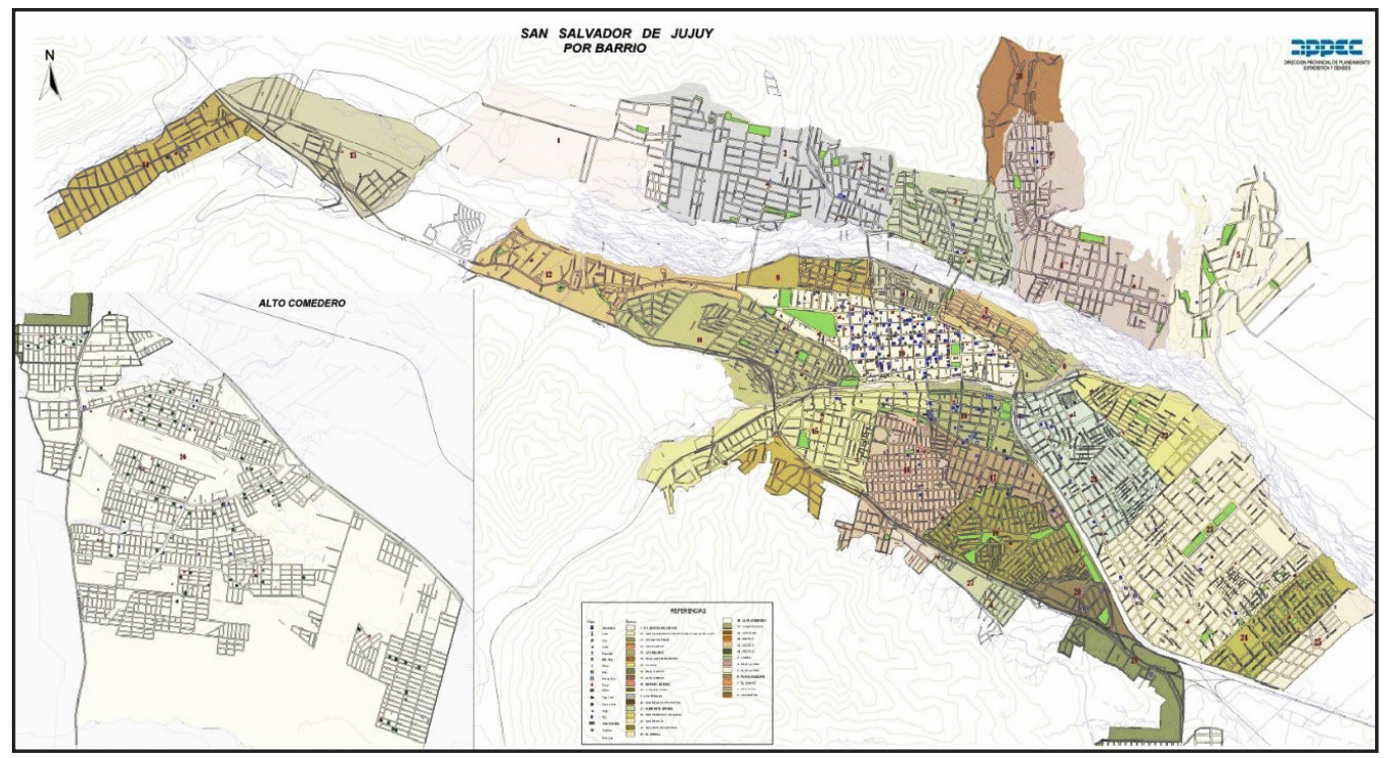

Fuente: DiPEC (s.f.). Recuperado de http://www.dipec.jujuy.gov.ar/cys_cartografiadigital/ cartografiaurbana/ssfinal.pdf

La influencia topográfica es un condimento más a la hora de pensar a la ciudad, no solo por estos ríos que hacen de tabiques en la programación urbanística, sino también por toda la serie de desniveles, cerros, depresiones y veras que han sido condición de toda la expansión territorial capitalina. Cuando García Vargas (2009, p. 156) hace mención a una ciudad en la que según los medios "hace falta espacio" (y modernidad) se refiere también a las dificultades que presenta (y el esfuerzo económico que supone) el terreno físico de cara a la construcción y habitabilidad. Y porque buena parte de la tierra disponible pertenece a terratenientes y a capitales empresariales privados. Este fenómeno no se restringe al territorio de la capital, sino que en una provincia signada por el monocultivo terrateniente, la minería a gran escala y la patrimonialización de la zona de quebrada - con la consecuente escalada de la propiedad turística para el lucro privado— ha ido "achicando" la disponibilidad de la tierra para sus propios habitantes. ${ }^{13}$

\footnotetext{
${ }^{12}$ El turismo en la capital provincial no tiene parangón con los enormes flujos que transitan por la región de la Quebrada de Humahuaca y, entre los atractivos ofrecidos a nivel local solo se cuentan unos cuantos edificios gubernamentales, iglesias y algunos hitos históricos del periodo independentista concentrados en su mayoría alrededor o en las proximidades de la plaza Belgrano (Gaona, 2014).

${ }^{13}$ Los últimos dos episodios de mayor repercusión en la disputa por la tierra en Jujuy se dieron en los años 2011 y 2012. El primero, en julio del 2011, en la ciudad de Libertador Gral. San Martín, más específicamente,
} 
Los puentes que conectan al casco céntrico con el resto de la ciudad operan como arterias conectoras de los distintos sectores y barrios, y por ellos confluyen los tránsitos entre los ámbitos barriales, y el comercio, el empleo y el ocio. A grandes rasgos puede considerarse que al norte del centro se encuentran las clases más acomodadas, las imágenes más pintorescas dentro de la ciudad y la mejor calidad de acceso a los servicios; en la zona sur, en cambio, se concentra la cuota más popular y populosa de la población local con un manifiesto déficit en el acceso a infraestructura (Bergesio, Golovanevsky y Marcoleri, 2009a).

La marcada "estatalidad" en la conformación del casco céntrico de la ciudad, sobre todo en el sector más patrimonializado en ella, se corresponde en buena medida con los designios del espacio público metropolitano, de acuerdo con lo planteado por Gorelik (1998). La casa de gobierno, la catedral, la policía provincial (ex cabildo), la legislatura provincial, edificios de orden público, el mercado artesanal, el shopping, el histórico edificio del diario Pregón y la peatonal representan nodos vitales en la experiencia jujeña, todos los cuales orbitan en torno o próximos a la plaza Belgrano, plaza principal de la ciudad.

La fractura urbana acentuada a partir de 1990 hace parte de las lógicas del tipo de ciudad configurada a partir del neoliberalismo (Grimson, Ferraudi y Segura, 2009; Svampa, 2001) (ver Figura 3). Para establecer a trazo grueso el modo en que se estructuró la ciudad de San Salvador de Jujuy, retomamos algunos de los puntos planteados por García y Echenique (1990), y retomados por Bergesio, Golovanevsky y Marcoleri (2009a), para señalar las divisiones socioeconómicas espaciales generadas en la ciudad:

- División Centro-Periferia: El nivel socioeconómico de los habitantes va descendiendo a medida que uno se aleja del centro de la ciudad.

- División Norte-Sur: Al norte del río Grande viven los grupos más acomodados económicamente, mientras que al sur del río Xibi-Xibi los niveles socioeconómicos descienden.

- División Convexa-Cóncava: los grupos de menores ingresos se instalan "en los contornos de los lechos de los ríos, en los límites de las zonas inundables, a un nivel inferior del centro de la ciudad, mientras que las residencias de la burguesía ocupan las alturas del oeste y las laterales de las colinas del norte (Bergesio et al., 2009a, p. 48).

Esta "espacialización de la diferencia" (García, 2006, p. 6) también se tradujo manifiestamente en la señalada problemática habitacional a nivel local y provincial. Las brechas y contracciones topográficas se convirtieron así en anatomía de la topografía socioeconómica. La "falta de espacio" mencionada encontró un canal de ampliación mediante las estrategias de los sectores populares por "ganar" terreno y tierra, no sin dificultades en la disputa por las parcelas, inaccesibilidad a servicios básicos y transporte, o condiciones de vivienda digna. Hablamos de una escalada de la acción de los sectores populares teniendo como resultado una masiva expansión de

en terrenos propiedad del Ingenio Ledesma, cuando unas quinientas familias accionaron para la ocupación de 15 hectáreas requeridas desde hacía años a la empresa, la cual tiene cercada a la localidad entera por terrenos de su propiedad. La toma y la intervención para el desalojo por parte de la policía, dejaron un saldo de cuatro muertos. El segundo episodio, también en el interior de la provincia, en este caso en Humahuaca, se dio a modo de enfrentamiento entre representantes de la organización social Tití Guerra y vecinos de la localidad, dejando como saldo trágico una muerte. 
Figura 3: Imagen panorámica de Jujuy

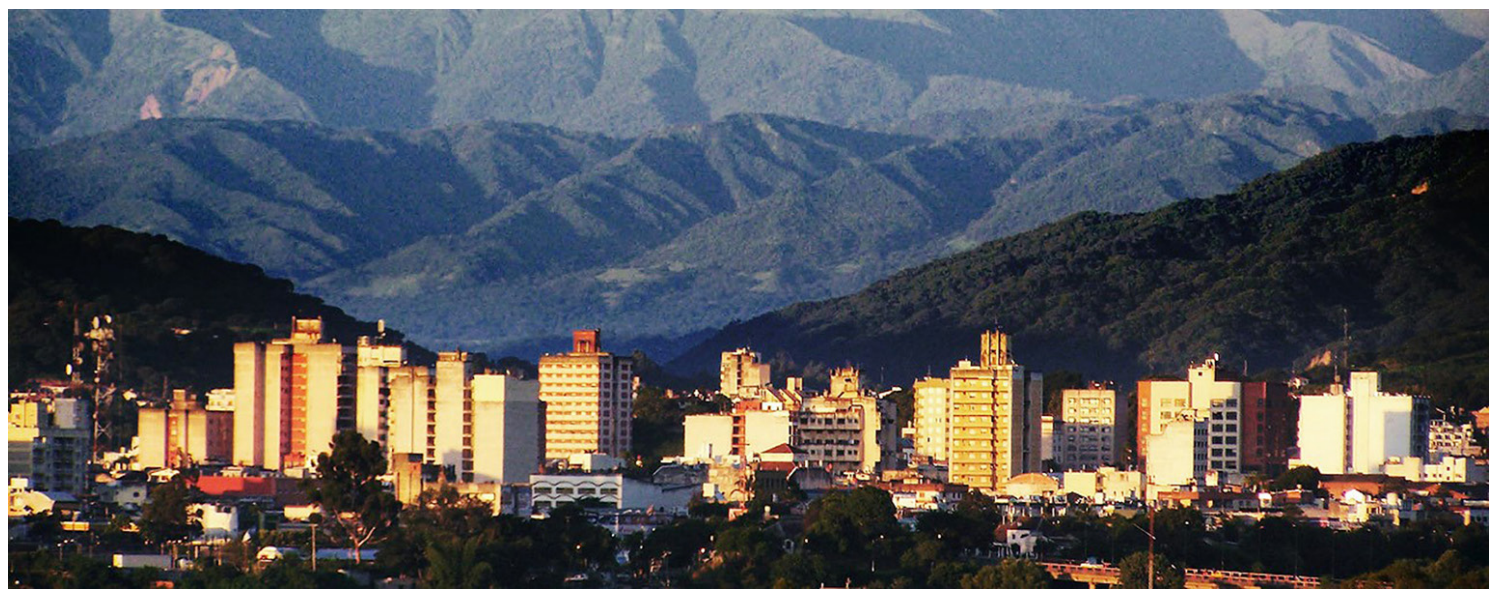

Fuente: La Gaceta Cristiana. (s.f.). Recuperado de http://www.gacetacristiana.com.ar/wp-content/ uploads/2015/05/jujuy.jpg

los asentamientos populares (García y Echenique, 1990) que se ubican en territorios poco valorados por planificadores estatales y sectores de mayores recursos: márgenes de los ríos y arroyos, laderas de montañas, zanjones, al costado de las rutas y caminos, ubicados cerca del sector administrativo y de mayor acceso a recursos (ver Figura 4).

Figura 4: Asentamiento popular desmembrado

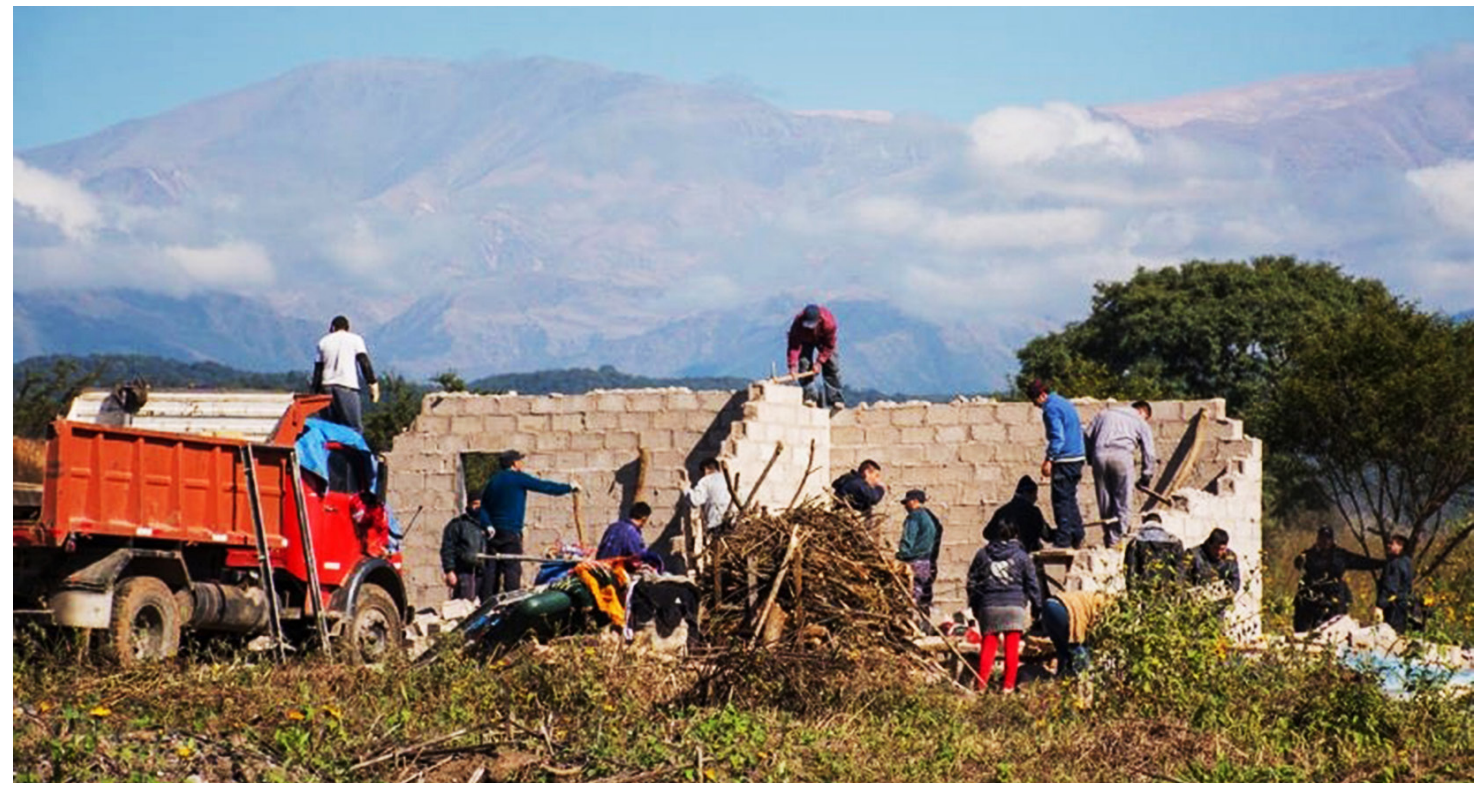

Fuente: Diario digital El Libertario.com Noticias de Jujuy. (2016). Recuperado de http://www. ellibertario. com/2016/06/08/desalojo-600-usurpadores-alto-comedero/ 


\section{El fenómeno de Alto Comedero}

El caso paradigmático de esta expansión popular es Alto Comedero (Figura 5). Este barrio, con orígenes desde apenas 1986, ubicado a unos cinco kilómetros del centro de la ciudad, reúne según las estimaciones censales casi un tercio de los habitantes de la ciudad, es decir, alrededor de unas setenta mil personas. Se convierte en la actualidad en el barrio más poblado de la ciudad y el de mayor propagación geográfica.

Figura 5: Cantidad de habitantes por barrio

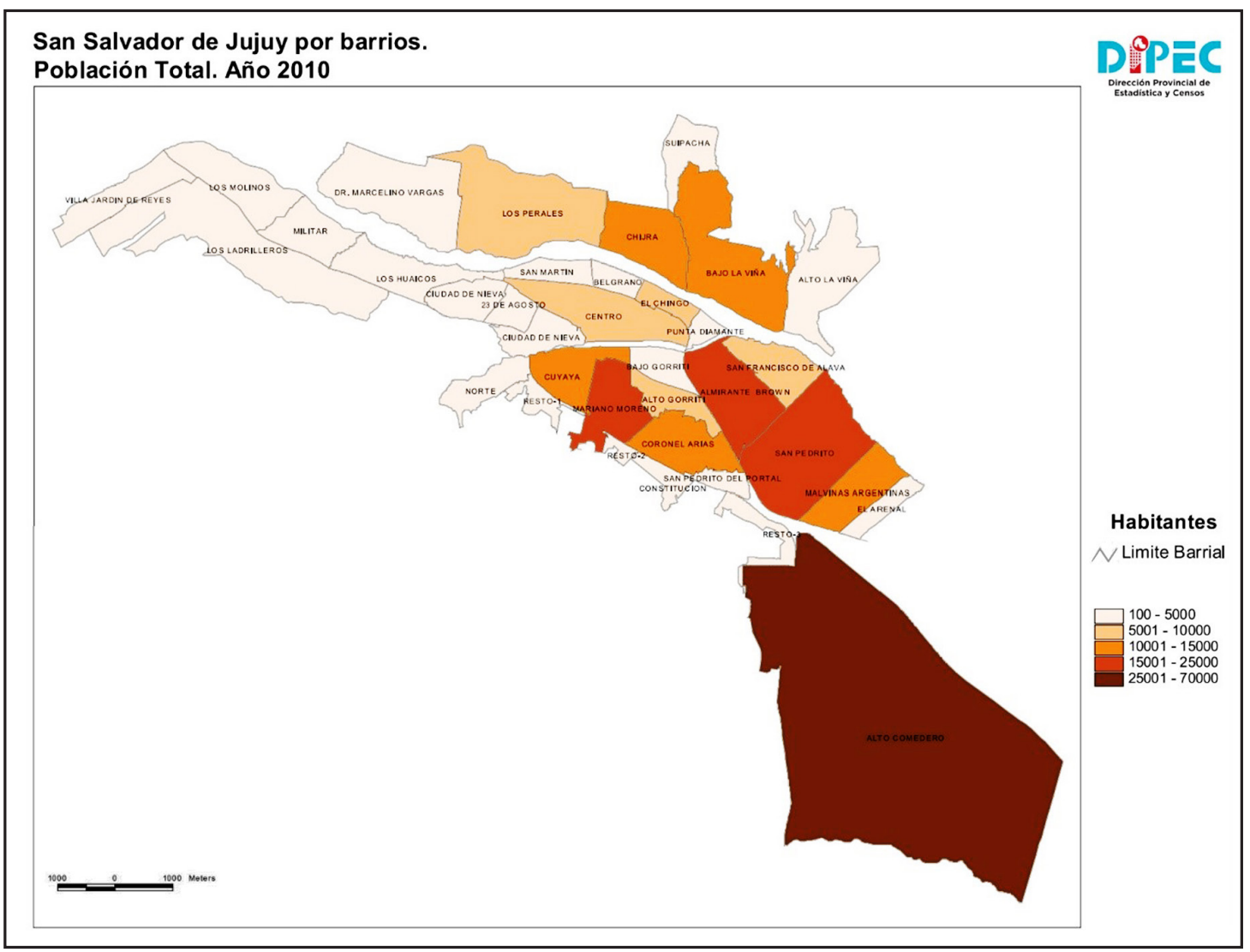

Fuente: DiPEC. Recuperado de http://www.dipec.jujuy.gov.ar/idx_barrios/san_salvador/mapas/ pobtotalssdejujuy.pdf

El carácter que adquieren sus formas de desarrollo y habitación habla a las claras del requerimiento de vivienda como fenómeno local, por otra parte, reconocible en distintas latitudes latinoamericanas.

Este terreno elevado respecto del resto de la ciudad, con desniveles y suelo arcilloso, sostiene como centro originario y jamás expropiado, al aeroclub local. Este punto no es solo central geográficamente, sino que ha sido territorio nodal de disputas entre las tomas de tierras periurbanas producidas en toda la provincia desde 2011. La 
diversidad que ha operado en la expansión del barrio habla también a las claras del modo de intervención que elige el Estado en los espacios periféricos de la ciudad. ${ }^{14}$ Es así una conjugación entre ocupaciones de terrenos privados y loteos fiscales con construcción de viviendas precarias, loteos privados, viviendas construidas por el Instituto de Vivienda y Urbanismo de Jujuy (IVUJ), con financiamiento del Banco Hipotecario Nacional, y por cooperativas de trabajo mediante programas nacionales mediados por las organizaciones sociales (esta última modalidad implementada recién a partir del año 2004) (Fournier, 2002; Gaona, 2011). La intervención por parte de los gobiernos para la expansión barrial, sobre todo en periodos electorales, no se condijo con apropiadas ampliaciones en los márgenes hasta donde llegan organizadamente los servicios.

En Alto Comedero se multiplican los reclamos por la escasa presencia de escuelas públicas, la exigüidad de servicios de seguridad regulares, la ineficacia del "puesto de salud grande" (como se llama al hospital allí radicado, gran edificio sin insumos y con poco personal), la ausencia de fuentes de trabajo, la escasez de transporte público y la carencia de pavimentación (Bergesio y Golovanevsky, 2010, p. 120).

Existe en la evolución de ambos ámbitos a lo largo de las últimas décadas, el casco céntrico y la conformación del barrio Alto Comedero, una fuerte intervención de un Estado que legitima a cada decisión un modelo de jerarquización de los espacios a través de la calidad de vida, la acentuación de las distancias a pesar de su relativa cercanía y el tipo de ciudadano que, se espera, acceda a uno u otro. Son dos ciudades al interior de una: la que está entre los dos ríos y el logotipo de la ciudad hace funcionar metonímicamente como "la" ciudad ${ }^{15}$; y la otra, aquella en la que "implosiona"16 la población desde distintos puntos de la ciudad, la región y la provincia.

\section{Sentidos de ciudad en disputa}

\section{Construcción del espacio mediático jujeño}

Como parte de la reconstrucción cartográfica de la ciudad, es también importante considerar los sentidos que de Jujuy se elaboran en el espacio mediático, pues este:

Resulta co-constitutivo del espacio social - y de sus vínculos con el espacio físico- ya que no se limita a dar forma a algo previo y ya existente sino que es parte del proceso de formación, estabilización, crítica o ruptura de la mayor parte de las figuras que se presentan al debate social (García, 2011, p. 47).

\footnotetext{
${ }^{14}$ Existe una puja histórica desde distintos sectores políticos en la ciudad por intentar municipalizar Alto Comedero. Durante 2015 se presentó el tercer proyecto que procura llevar adelante el nuevo municipio; sin embargo, de acuerdo con declaraciones mediáticas, este, como los anteriores intentos, no cuenta con el apoyo municipal ni provincial.

${ }^{15}$ García (2003), en un análisis semiótico acerca de los mapas de la ciudad, analiza el logotipo de la Municipalidad de San Salvador de Jujuy que ilustra únicamente los dos ríos y nueve cuadras al interior de ellos.

${ }^{16}$ Bergesio et al. (2009a) atribuyen el desborde habitacional experimentado en Alto Comedero a la marea inmigratoria proveniente de distintos sectores de la provincia a partir de la crisis socio-económica.
} 
En la reconstrucción de los sentidos hegemónicos de la ciudad, un relato especialmente eficaz como constructor y reproductor de mensajes que influyen en la manera en que nos representamos el mundo en que vivimos y nuestro entorno es aquél que producen los medios masivos de comunicación.

Aún en ciudades medianas, como la que se analiza, se comprende que la experiencia está atravesada y se hace inteligible en gran medida en los términos en los que los medios suministran la base de las "imágenes" de la vida, las prácticas y los valores de los grupos y clases; y las imágenes, representaciones y valoraciones que hacen a la totalidad social (Hall, 2010b).

Los medios masivos de San Salvador de Jujuy construyen un sentido hegemónico para la ciudad y para la gente que habita esa ciudad (Burgos y García, 2008; García, 2004, 2010b). La presentan como:

Una ciudad argentina, que es la capital de una provincia de frontera, que en ella hace falta espacio y modernidad, y también que es necesario recordar el pasado [un pasado vinculado con el heroísmo de los locales durante el proceso de independencia nacional]. (...) La ciudad se construye por oposición a otras (a algunas otras: Buenos Aires y Salta), ${ }^{17}$ a la naturaleza (que es también una especial naturaleza: los paisajes patrimonializados de la Quebrada de Humahuaca), y se ubica en un espacio nacional (cuyo exterior constitutivo se restringe a uno de los países fronterizos: Bolivia) (García, 2010b, p. 86). ${ }^{18}$

Además de algunos de los factores externos mencionados que influyen en la construcción mediática de la ciudad, operan interpretaciones acerca de lo internamente visible y no visible. Es así como mediante una operación de recorte espacial la ciudad es circunscripta a su centro histórico y comercial. Esta identificación de la ciudad con su centro:

Elude la mostración de los barrios, que se restringen en cambio a las noticias sobre infraestructura -basadas generalmente en partes de prensa de los organismos públicos- o bien al espacio de las crónicas policiales (...). El mapeo de hombres y mujeres que hacen los medios reproduce la espacialización diferencial de actores, asignando lugares desfavorables para quienes escapan del rol de ciudadanos ideales para la igualmente idealizada ciudad de San Salvador de Jujuy (García Vargas, Gaona y López, 2016, p. 96).

Aquello que no queda idealizado, que queda fuera de la norma, aparece en noticias encuadradas en las secciones policiales y tiene que ver con otros sectores

\footnotetext{
${ }^{17}$ La ciudad de Salta se ubica a alrededor de 100 kilómetros de distancia y es la capital de la otra provincia que limita con Bolivia y Chile en Argentina.

${ }^{18}$ Otro faceta en esta caracterización hegemónica acerca de Jujuy —en contraste con otros lugares, culturas y hábitos - que retomamos de manera lateral desde la mirada de un ensayista habla de:
}

\begin{abstract}
Esa otra Argentina, que no veranea en Punta del Este [Uruguay], pero que realiza, con la participación de vastos sectores populares, la fiesta del Tantanakuy; que no posee, como Buenos Aires, una de las concentraciones más altas del mundo, por habitante, de psicoanalistas, psiquiatras y psicólogos, y que, sin embargo, conserva profundos sentimientos religiosos, donde el cristianismo termina por perderse, sincretismo mediante, en la noche de los tiempos y donde, con excesiva frecuencia, los curanderos reemplazan a los médicos (Espejo, 2006, p. 25).
\end{abstract}


que no son ese centro: la zona de la terminal de ómnibus, los barrios de la zona sur o de los distintos sectores populares de la ciudad (García, 1999). Y aquello que tiene que ver con la gestión del Estado, la obra pública que apunta a la resolución de necesidades urgentes, también se presenta en esos otros sectores; mientras que el embellecimiento, la puesta en valor y patrimonialización es presentado en el ámbito céntrico público.

A esta modalidad de construcción del espacio jujeño capitalino debemos agregar otro lente con igual influencia. Nos referimos a aquella mirada y modos de decir frente al norte del país por parte de los medios de la ciudad de Buenos Aires, que operan como medios "nacionales" en el espectro de recepción y consumos a nivel federal. En este caso, las imágenes generadas plantean una operación de sinécdoque que hace opaca la diferencia provincia-ciudad, y en general suelen reportar casi exclusivamente circunstancias que tienen que ver con situaciones de criminalización de la frontera (López, 2013), visibilización de la pobreza, o escenas de violencia social sobre todo en órbitas de la política de mano de las organizaciones sociales (Gaona, 2016). También es recurrente la presentación de lo rural-paisajístico-turístico en imágenes de la Quebrada de Humahuaca.

\section{Articulaciones discursivas identitarias hegemónicas locales}

El vínculo con el resto del país se experimenta de manera compleja e inclusive conflictiva. La demanda por el reconocimiento como parte del territorio nacional se abre en el abanico de instancias reproductivas locales, tanto en lo mediático masivo (Burgos y García, 2008), como en eventos deportivos (Burgos, 2014), en festividades determinantes de la cultura popular jujeña, como son la Fiesta Nacional de los Estudiantes (Ficoseco, 2007) o la fecha patria del Éxodo Jujeño ${ }^{19}$ (Gaona, 2015; Maya, 2014), y suele sostenerse como horizonte simbólico presente en los conflictos políticos, de beligerancia popular y ante cualquier cruce por delimitar selectivamente qué significa "ser jujeño" (Figura 6).

Una común caracterización analítica utilizada en los estudios acerca de identidades en torno de lo jujeño es aquella que elaboraran Belli y Slavutsky, la cual, a riesgo de parecer una apreciación que por escueta puede tener atisbos esencialistas por discutir, sirve como presentación de algunos de los elementos recurrentes en la autoidentificación local/provincial. Para estos autores, ser jujeño:

Puede tomar el orden jurídico — se es jujeño porque se nació aquí- donde la identificación distingue entre quien nació y permaneció en la provincia de aquellos que fueron migrantes temporarios. Otro modo enunciativo de marcar la identidad jujeña, por parte de los agentes es indicar rasgos, signos distintivos: el jujeño ama su tierra, celebra con unción 'el éxodo jujeño', es muy católico y venera a sus santos, etc.: o bien señala diferencias nítidas (que

\footnotetext{
${ }^{19}$ Por ejemplo, en el caso de la evocación del Éxodo y de las diferentes performances que 'reconstruyen' los eventos históricos, se presentan imágenes como parte de la tradición jujeña que de hecho no requieren de interlocución con algún pasado, sino más bien del margen suficiente para la habilitación al fijar los símbolos con los cuales sería posible imaginarse signos visibles que perdurarían de tal pasado como parte del relato nacional.
} 
suelen tomar la forma de oposiciones) con la vecina provincia de Salta y con los sureños, especialmente marcado para el caso de cordobeses y porteños (Belli y Slavutsky, 1994, p. 121).

Se comprende que al hablar de identidades hablamos de articulaciones hegemónicas en el marco de los procesos de reconocimiento e identificación en pugna, en los que diferentes formas de representación, trabajo discursivo y demarcación de límites simbólicos (Hall, 1997) operan estableciendo, no solo cierta reciprocidad constitutiva entre diferentes grupos como orden de sostenimiento, sino también la configuración contingente y localizada de jerarquizaciones entre grupos "señalables" (Hall, 2010a).

Estas jerarquizaciones se establecen con un horizonte permanentemente en conflicto en lo local; el reclamo de pertenencia nacional:

No es naturalmente unívoco y constituye un espacio político ideológico donde se enfrentan fuertes contradicciones. Bajo ciertas condiciones podrán priorizarse los aspectos más reaccionarios del discurso de la nacionalidad (la adhesión a la cultura oficial, la hostilidad contra los bolivianos), pero bajo otras condiciones puede representar la demanda de participación y democratización real de la sociedad, al amparo (de) la común membresía al sistema político (Karasik, 1994, p. 69).

Figura 6: Actos evocativos del Éxodo Jujeño

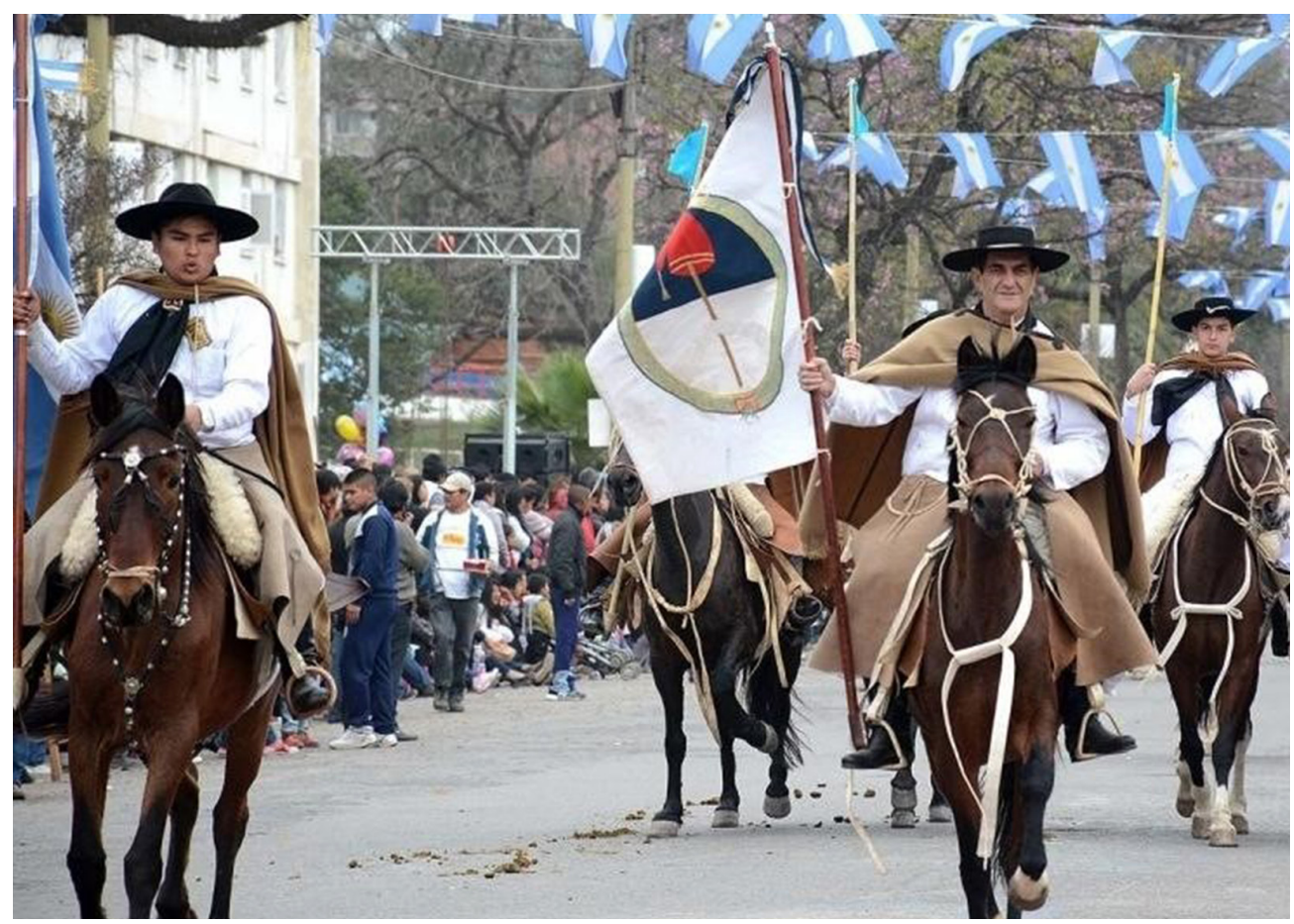

Fuente: Jujuy al Momento. com. Recuperado de http://www.jujuyalmomento.com/upload/img/120agrupaciones-gauchas-formaron-parte-del-desfile-por-el-exodo-jujeno-20786_2505.jpg 
Esa identificación está trasvasada por lo que suponen los cuerpos mismos, como movimiento fronterizo entre lo que "son" y lo que los constituye por fuera de sus límites (Butler, 2008). Esa materialización depende de la propiedad reiterativa que se introduce como régimen de verdad discursivo. La formulación material existe en la medida en que su espacio de inscripción se delimita por aquello que excluye. Así, la demanda inclusiva respecto del resto del país apela a una configuración excluyente de algunos elementos internos (Gaona, 2015).

La aparente incomodidad con la que se asume la identificación nacional en el contexto jujeño implica que "hacerse" argentino exhorte a retomar mediante símbolos del tradicionalismo nacional los medios para borrar ciertas marcas negativamente valoradas. En el intento por desprenderse de la condición de extranjería dentro del propio territorio nacional se procura renunciar a todas aquellas instancias de la propia materialización local que aludan a lo liminar y fronterizo.

El reconocimiento, los estatutos de la existencia más legítima y más habitable, no solo hacen ponderar ciertos modos de ser ciudadanos, sino que accionan para velar a todos aquellos que aparezcan negados de ese pretendido ser. Eventos y festividades como los mencionados - la Fiesta Nacional de los Estudiantes y la evocación del Éxodo-apelan a la construcción de un "nosotros" que se construye también a partir de una exterioridad, ajenidad o alteridad que, si bien nublada, late constantemente tanto como parte del relato histórico, como de la imposición de un tipo de corporalidades admisibles en el presente.

Estos discursos se tejen conflictivamente entre lindar y vincularse culturalmente con Bolivia (mucho más que con Chile) en mayor medida que las demás provincias de la región norte; con el resto del país como un todo y con la capital federal como horizonte simbólico. Así también, en pugna por el reconocimiento de su condición nacional, los discursos hegemónicos de "la ciudad" se han caracterizado por un desenvolvimiento dentro de la apelación a la argentinidad por sobre los rasgos identificados como bolivianos; rasgos que en definitiva también aluden a su condición de ciudad surandina, diferente de la geografía de buena parte del país. Por otro lado, estos discursos se tensan en las disputas simbólicas con Salta, disputas que apelan al desarrollo y la "modernización" de ambas ciudades, las imágenes paisajísticas ofrecidas como símbolos del turismo, y a la etnificación y extranjerización como recursos de jerarquización.

Todas estas capas discursivas señalan parte del modo en el que la frontera territorial ha condicionado la propia construcción de la pertenencia, los procedimientos - no unívocos- para la identificación nacional, y la necesidad de purificación a partir de la tradicionalización de la cultura como parte de los elementos hegemónicos, por sobre las densidades de la mixtura étnica cultural, propia de la frontera.

\section{Sistematización de conceptos y conclusiones}

Este artículo ha procurado un estado de conocimiento acerca de la ciudad de San Salvador de Jujuy a modo de cimiento argumental de la hipótesis planteada respecto de la ciudad capital de Jujuy como espacio fronterizo en tensión con lo nacional. Esta hipótesis es inducida a partir del recurrente planteo político y social acerca de los conflictos de Jujuy en torno de su condición fronteriza y de periferia respecto de los centros políticos y comerciales del país. 
El texto fue organizado a partir de tres ejes principales: factores migratorios y sociopolíticos como parte de la historia local; expansión y configuración territorial urbana como "espacialización" de la disputa entre los sectores dominantes y los sectores populares; y los sentidos de ciudad hegemónicos sobre todo a partir de lo mediático y los rituales.

Cada uno de estos tres elementos hace parte a la materialidad histórica sobre la cual se cimienta en la actualidad San Salvador de Jujuy. La apuesta en este artículo ha sido sobre todo sistematizar parte de diferentes investigaciones sociales acerca de la ciudad y hacerlas confluir en diálogo para armar un mapa sobre los elementos que inciden en la cotidianidad de la experiencia urbana de frontera. Hemos considerado cada una de estas facetas de la red de discursos acerca de la ciudad para reconstruirla como un espacio social. Así, observamos que el espacio de ciudad San Salvador de Jujuy está permanentemente dinamizado por su condición de espacio fronterizo (de capital de una provincia fronteriza).

Podemos señalar que el proceso migrante boliviano y de puna y quebrada sostenido por más de un siglo condiciona permanentemente las adscripciones, tensiones y rechazos internos frente a la demanda por pertenencia nacional. También ha contribuido a una fuerte desarticulación y desbalance entre las zonas rurales más cercanas a la frontera y las regiones urbanas.

A nivel político esto ha sido traducido en un permanente clima de "ingobernabilidad" como fórmula por más de una década hacia fines del siglo pasado. Frente a gobiernos caudillistas débiles, la productividad política se vio sobre todo movilizada por los rumbos de los movimientos sociales locales.

La situación económica crítica de tintes crónicos se vio traducida también en un agravamiento de las marcas de desigualdad territorial. Se terminaron de consolidar en los espacios de ciudad una marcada distancia entre lo que acontece entre ambos ríos delimitantes del casco céntrico, y el resto de los barrios y asentamientos.

La ciudad y la región, signadas por la propiedad terrateniente a gran escala, han sufrido un "achicamiento" del suelo disponible para la habitabilidad y el acceso a la vivienda. Esto devino en una creciente expansión de asentamientos no planificados por el Estado en territorios poco aptos para la edificación y regiones periféricas sin servicios ni un buen acceso al transporte, con Alto Comedero como principal símbolo del fenómeno local. Tanto en la jerarquización de la calidad de los espacios céntricos patrimonializados como en la pauperización de la periferia expandida se distingue una fuerte intervención estatal que convalida un modelo de jerarquización de los espacios a través de la calidad de vida, la acentuación de las distancias a pesar de su relativa cercanía y el tipo de ciudadano que, se espera, acceda a uno u otro.

Este tipo de configuraciones de la ciudad también se reproducen y sostienen en el espacio mediático. Allí también se reproducen discursos hegemónicos concernientes tanto a la mirada interna, como al modo en el que se representa la ciudad (y la provincia) desde afuera. Se observa una distancia entre los medios locales y los provenientes de Buenos Aires dado que mientras uno se enfoca en considerar las cualidades de un tipo de habitantes idealizados y las distancias entre lo que acontece y se ve en el centro y la periferia de la ciudad; los otros, los medios rioplatenses, reproducen y aluden sobre todo a situaciones de criminalización de la frontera, visibilización de la pobreza regional, y a escenas de violencia vinculadas a los movimientos sociales.

La demanda por el reconocimiento como parte del territorio nacional se establece como elemento nodal de cada una de las instancias ritualizadas a nivel local (patrióticas, 
festivas, deportivas, culturales, etc.) La aparente condición de extranjería dentro del propio territorio nacional ubica incómodamente la condición fronteriza reafirmando a cada gesto la pertenencia como argentinos a fuerza de la exteriorización de algunos elementos internos.

Como fue mencionado anteriormente, históricamente los análisis de ciudad desde perspectivas socioculturales se han enfocado sobre todo en los fenómenos de crecimiento explosivo, en términos mercantiles de métrica comparativa —sea de manera simbólica cultural o productivo-material-, o en su más reciente campo de problemáticas a partir de los efectos tecnológicos en la experiencia urbana (Legates y Stout, 2016; Miles, Hall y Borden, 2004).

Por su parte, los estudios latinoamericanos han hecho foco en la trascendencia del signo colonial que ha hilado la historia de sus ciudades (Rama, 1998; Romero, 2010). Esto no sin dejar de observar que los ensayos históricamente más destacados acerca del territorio nacional argentino han estado abocados a la interpretación de las ciudades pampeanas-rioplatenses como elemento fundamental para el entendimiento de dicha condición colonial en el territorio nacional (Gorelik, 1998; Martínez, 1997; Sarmiento, 2011). Más recientemente, el interés por los efectos de la posmodernidad en las grandes urbes también ha dominado la escena local nacional (Carman, 2006; Sarlo, 2010; Svampa, 2001).

Para el caso de la ciudad de San Salvador de Jujuy, esta ha sido analizada tanto como resultado de procesos migratorios externos e internos; como ciudad con sentidos dominantes, como terreno político y como ciudad habitada, transitada y experimentada por sus habitantes; estos análisis desde diferentes disciplinas y con problemáticas variadas convergen en lo determinante del tenso desenvolvimiento local frente a la relación con lo regional y lo nacional. En esta agenda académica que también se representa a la ciudad - y hace de un elemento más acerca de sus sentidos- no han dejado de considerarse las distintas escalas geográficas que se ponen en juego: el territorio más próximo como factor determinante cultural, las incidencias nacionales y regionales más amplias en el desarrollo provincial, y la territorialización local a partir de las condiciones globalmente propiciadas. Se han analizado ya las consecuencias de los factores mercantiles neoliberales en un paradigma globalizado sobre el conjunto de la población, sobre todo en sus efectos dañosos para la habitabilidad del suelo (y de la vida en la ciudad) por parte de los sectores no hegemónicos. Resta indagar con mayor profundidad de qué manera este tipo de ciudad con sus demandas de pertenencia termina conllevando dispositivos excluyentes y expulsivos de sus elementos internos.

\section{Referencias}

Belli, E. y Slavutsky, R. (1994). Flores, reinas y carrozas. Reflexiones sobre la identidad en San Salvador de Jujuy. En G. Karasik (Comp.), Cultura e identidad en el noroeste argentino (pp. 120-145). Buenos Aires, Argentina: Centro Editor de América Latina.

Benedetti, A. (2014). Espacios fronterizos del sur sudamericano. Propuesta de un modelo conceptual para su estudio. Estudios Fronterizos, 15(29), 11-47. Recuperado de http:/ / www.redalyc.org/articulo.oa?id=53031359001

Benjamin, W. (2005). Libro de los pasajes. España: Akal. 
Bergesio, L. y Golovanevsky, L. (2010). Crecimiento urbano y fragmentación social. Breve historia del surgimiento y expansión del barrio Alto Comedero. En A. García (Comp.), Ciudad. San Salvador de Jujuy como texto (pp. 115-123). San Salvador de Jujuy, Argentina: EDIUnJu.

Bergesio, L., Golovanevsky, L. y Marcoleri, M. E. (2009a). Construcción social de la ciudad. San Salvador de Jujuy desde el barrio Alto Comedero. San Salvador de Jujuy, Argentina: EDIUnJu.

Bergesio, L., Golovanevsky, L. y Marcoleri, M. E. (2009b). Privatizaciones y mercado de Trabajo: La venta de empresas públicas en Jujuy y sus consecuencias sobre el empleo. En M. Lagos (Dir.), Jujuy bajo el signo neoliberal. Política sociedad y cultura en la década del noventa (pp. 185-249). San Salvador de Jujuy, Argentina: EDIUNJu.

Bolle, W. (2008). Metrópolis y megaciudades: sobre el ordenamiento del saber en los Pasajes de Walter Benjamin. En R. Buchenhorst y M. Vedda (Eds.), Observaciones urbanas: Walter Benjamin y las nuevas ciudades (pp. 17-52). Buenos Aires, Argentina: Gorla.

Burgos, R. (2014). Fútbol y política. El club Gimnasia y Esgrima y la construcción de una identidad jujeña (1975-2011) (Tesis doctoral inédita). Universidad Nacional de La Plata, La Plata, Argentina.

Burgos, R. y García, A. (2008). El irrenunciable desafío de trabajar por Jujuy y su gente. Actores, cultura e identidad en el suplemento ' 50 aniversario de Pregón'. Oficios Terrestres, (21), 80-91.

Butler, J. (2008). Cuerpos que importan. Sobre los límites materiales y discursivos del sexo. Buenos Aires, Argentina: Paidós.

Caggiano, S. (2005). Lo que no entra en el crisol: inmigración boliviana, comunicación intercultural y procesos identitarios. Buenos Aires, Argentina: Prometeo libros.

Carman, M. (2006). Las trampas de la cultura: Los 'intrusos' y los nuevos usos del barrio de Gardel. Buenos Aires, Argentina: Paidós.

Dirección Provincial de Estadísticas y Censos (DiPEC). (2012). Población por censos según departamento. Provincia de Jujuy. Censos 1869-2010. En Anuario Estadístico de la Provincia de Jujuy. Recuperado de http:/ / www.dipec.jujuy.gov.ar/idx_anuario/anuario2012_c2.pdf

Espejo, M. (2006). Introducción: la memoria recobrada. En A. Teruel y M. Lagos (Dir.), Jujuy en la historia. De la colonia al siglo xx (pp. 15-36). San Salvador de Jujuy, Argentina: EDIUnju.

Ficoseco, V. (2007). La construcción de la imagen de la mujer en la prensa gráfica de Jujuy durante la Fiesta Nacional de los Estudiantes (Tesis inédita). Universidad Nacional de Jujuy, Jujuy, Argentina.

Foucault, M. (2006). Seguridad, territorio, población: Curso en el Collège de France: 19771978 ( $\left.1^{\mathrm{a}} \mathrm{ed}\right)$. Buenos Aires, Argentina: Fondo de Cultura Económica.

Fournier, M. J. M. (2002). Ordres et désordresdans les villesargentines, l'exemple de Alto Comedero, San Salvador de Jujuy. Annales de Géographie, 111(624), 179-197.

Freitag, S. (2012). Teorías da cidade. Brasil: Papirus.

Gaona, M. (2011). Vida cotidiana y relaciones familiares en el barrio Tupac Amaru de San Salvador de Jujuy (Tesis inédita). Universidad Nacional de Jujuy, Jujuy, Argentina. 
Gaona, M. (2014). Tripear por San Salvador de Jujuy. La ciudad mirada desde una web de turistas y viajeros. Question, 1(44), 97-105. Recuperado de http:// perio.unlp. edu.ar/ojs/index.php/question/article/view/2281/2051

Gaona, M. (2015). Visibilidades, espacio social y mediático, y construcción de las identificaciones colectivas hegemónicas a partir de la evocación del pasado como relato del presente: El éxodo jujeño. Comunicación, 33, 29-43.

Gaona, M. (2016). Experiencia, ciudad e identidad en torno a la organización barrial Tupac Amaru en San Salvador de Jujuy (Tesis doctoral inédita). Universidad Nacional de La Plata, La Plata, Argentina.

Gaona, M. y López, A. (2013). Género, comunicación y cultura. En dos organizaciones sociales de San Salvador de Jujuy. San Salvador de Jujuy: EDIunju.

García, A. (1999). "Señores, el Mercado es la cara de cada pueblo". El uso de la Banca XIII en relación con el conflicto por la privatización del Mercado Central Municipal de San Salvador de Jujuy. Actas de la Tercer Reunión de Antropología del MERCOSUR (III RAM). Posadas, Argentina: Universidad Nacional de Misiones.

García, A. (2000). San Salvador de Jujuy: Distribución en el espacio y posibilidades de acceso a instituciones sanitarias. En Informe Argentino sobre Desarrollo Humano (pp. 20-22). Buenos Aires, Argentina: Programa de las Naciones Unidas para el Desarrollo, Senado de la Nación Argentina.

García, A. (2003). La iconicidad como estrategia metodológica: mapas y planos de San Salvador de Jujuy. Signo y Pensamiento, 22(43), 153-163.

García, A. (2004). Traducciones. Multiculturalidad, espacio físico y espacio social en la patrimonialización de San Salvador de Jujuy durante la década de 1990. En A. Alfonso, F. Saintout y M. Krohling, Ponencias 70 años de Periodismo y Comunicación en América Latina. La Plata, Argentina: Universidad Nacional de La Plata.

García, A. (2006). En construcción. Geografías del poder y sentidos del lugar en San Salvador de Jujuy. UNIRev Actas del VII Congreso ALAIC y VIII Congresso Latino-americano de Pesquisadores de Comunicaçao. São Leopoldo, Rio Grande do Sul, Brasil.

García, A. (2009). Geografías del poder. Comunicación transnacional y estudios interculturales en la periferia globalizada. Memoria Encuentro Internacional Comunicación y Cultura "Interculturalidad, globalización y comunicación" (pp. 151-167). La Paz, Bolivia: Fundación Visión Cultural.

García, A. (2010a). San Salvador de Jujuy: una, otra, esta ciudad. En A. García (Comp.), Ciudad. San Salvador de Jujuy como texto (pp. 13-22). Jujuy, Argentina: EDIUnju.

García, A. (2010b). "Tan lejos, tan cerca..." Medios masivos e inmigración boliviana en San Salvador de Jujuy. Con-Sciencias Sociales, (2), 83-94.

García, A. (2011). Mapas clásicos y parecidos de familia en la producción comunicacional latinoamericana sobre ciudades. Suplemento especial de Cuadernos, (39).

García, A., Arrueta, C. y Brunet, M. (2009). Medios masivos: tramas y complicidades en Jujuy. Una mirada desde la década del 90. En M. Lagos (Dir.), Jujuy bajo el signo neoliberal. Política sociedad y cultura en la década del noventa (pp. 503-545). San Salvador de Jujuy, Argentuina: EDIUnJu.

García, A., Gaona, M. y López, A. (2016). Intersecciones: espacio físico, social y mediático en la construcción cotidiana de una "ciudad ordinaria" en San Salvador de Jujuy, Argentina. Comunicación y Medios, 25(33), 89-114. Recuperado de 
http://www.comunicacionymedios.uchile.cl/index.php/RCM/article/viewFile $/ 37236 / 43468$

García, M. (2010). De la cuadrícula de control a la gran ciudad. En A. García (Comp.), Ciudad. San Salvador de Jujuy como texto (pp. 55-68). San Salvador de Jujuy, Argentina: EDIUNJu.

García, M. y Echenique, M. (1990). Lógica de la localización de los pobres urbanos en Jujuy. Cuadernos, 2, 9-11.

Gorelik, A. (1998). La grilla y el parque. Espacio público y cultura urbana en Buenos Aires, 1887-1936. Bernal, Argentina: EDUNQ.

Grimson, A. (2000). Introducción: ¿fronteras políticas versus fronteras culturales? En A. Grimson (Comp.), Fronteras, naciones e identidades. La periferia como centro (pp. 9-40). Buenos Aires, Argentina: Ciccus, La Crujía.

Grimson, A. (2009). Introducción: clasificaciones espaciales y territorialización de la política en Buenos Aires. En A. Grimson, M. Ferraudi y R. Segura (Comps.), La vida política en los barrios populares de Buenos Aires (pp. 11-38). Buenos Aires, Argentina: Prometeo Libros.

Grimson, A., Ferraudi, M. y Segura, R. (Comps.). (2009). La vida política en los barrios populares de Buenos Aires. Buenos Aires, Argentina: Prometeo Libros.

Grossberg, L. (2006). Stuart Hall sobre raza y racismo: estudios culturales y la práctica del contextualismo. Tabula Rasa, (5), 45-65.

Hall, S. (1997). Representation. Cultural representations and signifying practices. Londres: Sage Publications.

Hall, S. (2010a). ¿Qué es lo negro en la cultura popular negra? En E. Restrepo, C. Walsh y V. Vich (Eds.), Sin garantías: trayectorias y problemáticas en estudios culturales (pp. 287-297). Bogotá, Colombia: Envión Editores.

Hall, S. (2010b). La cultura, los medios de comunicación y el 'efecto ideológico'. En E. Restrepo, C. Walsh y V. Vich (Eds.), Sin garantías: trayectorias y problemáticas en estudios culturales (pp. 221-254). Bogotá, Colombia: Envión Editores.

Instituto Nacional de Estadísticas y Censos (Indec). (2012). Censo Nacional de Población, Hogares y Viviendas 2010: censo del Bicentenario: resultados definitivos (serie B No2. tomo 1). Buenos Aires, Argentina: Autor.

Jerez, M. (2015). El problema de la vivienda en San Salvador de Jujuy en la primera mitad del siglo xx. En A. García (Comp.), Territorios y sentidos de ciudad. San salvador de Jujuy, la capital provincial (pp. 33-49). San Salvador de Jujuy, Argentina: EDIUnJu.

Jerez, O. y Rabey, M. (2006). Ciudades de frontera e industria azucarera. Cuaderno Urbano, (5), 7-33. Recuperado de http://www.redalyc.org/pdf/3692/369236766001.pdf

Karasik, F. y Gómez, E. (2015). La empresa Ledesma y la represión en la década de 1970. Conocimiento, verdad jurídica y poder en los juicios de lesa humanidad. Clepsidra, (3), pp. 110-131. Recuperado de http://memoria.ides.org.ar/revista-clepsidra/clepsidra-no-3

Karasik, G. (1994). Plaza grande y plaza chica: etnicidad y poder en la Quebrada de Humahuaca. En G. Karasik (Comp.), Cultura e identidad en el noroeste argentino (pp. 35-75). Buenos Aires, Argentina: Centro Editor de América Latina.

Karasik, G. (2005). Etnicidad, cultura y clases sociales. Procesos de formación histórica de la conciencia colectiva en Jujuy, 1970-2003 (Tesis doctoral inédita). Universidad Nacional de Tucumán, Tucumán, Argentina. 
Kingard, F. (2009). Los conflictos sociales bajo la política neoliberal. En M. Lagos (Comp.), Jujuy bajo el signo neoliberal. Política, sociedad y cultura en la década del noventa (2a ed., pp. 311-355). San Salvador de Jujuy, Argentina: EDiunju.

Lagos, M. y Gutiérrez, M. (2006). Dictadura, democracia y políticas neoliberales. 19761999. En A. Teruel y M. Lagos (Dir.), Jujuy en la historia. De la colonia al siglo XX (pp. 243-294). San Salvador de Jujuy, Argentina: EDIUnju.

Lagos, M. y Gutiérrez, M. (2009). La década del menemismo y la ingobernabilidad en Jujuy. Nación, región y provincia en los noventa. En M. Lagos (Comp.), Jujuy bajo el signo neoliberal. Política, sociedad y cultura en la década del noventa $\left(2^{\mathrm{a}}\right.$ ed., pp. 65-124). San Salvador de Jujuy, Argentina: EDiunju.

Legates, R. y Stout, F. (2016). The city reader (6 $6^{\mathrm{a}}$ ed.). Estados Unidos: Routledge.

López, A. (2011). La participación de las mujeres en el movimiento social y cultural Tupaj Katari (Tesis inédita). Universidad Nacional de Jujuy, Jujuy, Argentina.

López, A. (2013). "Dime quien te mira y te diré quién eres". La construcción discursiva hegemónica de las mujeres 'bagayeras' de las fronteras argentino-bolivianas. Actas digitales del xv Redcom, San Salvador de Jujuy, Argentina.

Martínez, E. (1997). Radiografía de la Pampa (2a ed.). España: Edición Crítica.

Martínez, R., Golovanevsky, L. y Medina, F. (2010). Economía y empleo en Jujuy. [Monografía]. Colección Documentos de Proyecto. Santiago, Chile: CEPAL.

Massey, D. (2005). For Space. Gran Bretaña, Reino Unido: Sage Publications.

Maya, R. (2014). La construcción de la figura del gaucho en la radio de San Salvador de Jujuy. Los casos de los programas "Tradiciones gauchas" y "El orejano" (Tesis inédita). Universidad Nacional de Jujuy, Jujuy, Argentina.

Miles, M., Hall, T. y Borden, I. (2004). The city culture reader (2a ed.). Estados Unidos: Routledge.

Rama, A. (1998). La ciudad letrada. Uruguay: Arca.

Rodríguez, M. (2002). La parte de los que no tienen parte. La dimensión simbólica y política de las protestas sociales: la experiencia de los piqueteros en Jujuy. Buenos Aires, Argentina: Centro Cultural de la Cooperación.

Romero, J. L. (2010). Latinoamérica. La ciudad y las ideas ( $3^{\mathrm{a}}$ ed.). Buenos Aires, Argentina: Siglo xxi Editores.

Sala, G. (2012). Acciones sanitarias dirigidas a los migrantes bolivianos residentes en Jujuy durante los años noventa. Cuadernos, (41), 273-292. Recuperado de http://cuadernos-fhycs.org.ar/testfhycs/index.php/cuadernos/article/ view/180/121

Sarlo, B. (2010). Tiempo presente ( $2^{\mathrm{a}}$ ed.). Buenos Aires, Argentina: Siglo xxi Editores. Sarmiento, D. F. (2011). Facundo. Buenos Aires, Argentina: Eudeba.

Sassen, S. (1999). The global city: New York, London, Tokyo. Gran Bretaña, Reino Unido: Princeton University Press.

Sassone, M. S. (2009). Breve geografía histórica de la migración boliviana en la Argentina. Temas de Patrimonio Cultural: Buenos Aires Boliviana. Migración, construcciones identitarias y memoria, (24), 389-402. Recuperado de http://buenosaires.gob.ar/ areas/cultura/cpphc/archivos/libros/temas_24.pdf

Simmel, G. (2004). The metropolis and the mental life. En M. Miles, T. Hall y I. Borden (Eds.), The city cultures reader (2a ed., pp.12-19). Gran Bretaña, Reino Unido: Routledge. 
Stumpo, G. (1992). Un modelo de crecimiento para pocos. El proceso de desarrollo de Jujuy entre 1960 y 1985. En A. Isla (Comp.), Sociedades y articulación en las tierras altas jujeñas, crisis terminal de un modelo de desarrollo (pp. 41-114). Buenos Aires, Argentina: MLAL.

Svampa, M. (2001). Los que ganaron. La vida en los countries y barrios privados. Buenos Aires, Argentina: Biblos.

\section{Melina Gaona}

Argentina. Doctora en Comunicación por la Universidad Nacional de La Plata y Licenciada en Comunicación Social por la Universidad Nacional de Jujuy. Becaria postdoctoral Conicet en el Centro de Estudios de Historia, Cultura y Memoria, Universidad Nacional de Quilmes. Docente de la Universidad Nacional de La Matanza. Líneas de investigación: ciudad, comunicación y el género desde la crítica cultural. Ha publicado los libros Experiencia popular, ciudad e identidad en el noroeste argentino. La organización social Tupac Amaru (2017) y Género, comunicación y cultura en dos organizaciones sociales, en coautoría con A. López (2013). 